\title{
Dynamic analyses of isolated structures under bi-directional excitations of near-field ground motions
}

\author{
Gokhan Ozdemir and Ugurhan Akyuz* \\ Department of Civil Engineering, Middle East Technical University, Ankara, Turkey
}

Received 2 November 2010

Revised 19 February 2011

\begin{abstract}
Nonlinear response history analyses (NRHA) of a 3-story isolated reinforced concrete (RC) building are carried out under both uni- and bi-directional earthquake excitations of near-field records. NRHA are conducted for a wide range of yield strength $(Q / W)$ of lead rubber bearings (LRB), and isolation period $(T)$. Selected near-field records are used to investigate both the contribution of orthogonal components on maximum isolator displacements and accuracy of equivalent lateral force (ELF) procedure on estimation of maximum isolator displacements. Analyses results show that both the contribution of orthogonal components and accuracy of ELF procedure depend on the soil condition where isolation system is implemented.
\end{abstract}

Keywords: Seismic isolation, near field records, lead rubber bearing, bi-directional analysis

\section{Introduction}

Important prediction for seismically isolated structures by using simplified methods, namely Equivalent Lateral Force (ELF) procedure, is the maximum isolator displacement of isolation systems. In this sense, ELF procedure is widely used by practicing engineers for preliminary and final design of seismically isolated structures [1]. This method is based on representative linear approximations of bi-linear isolator behavior. ELF procedure is a one-directional analysis based on response spectrum methods and when the effects of both orthogonal horizontal components are of concern, the prescribed method to incorporate the contribution of orthogonal component is the $100 \%+30 \%$ rule. This rule assures the simultaneous application of $100 \%$ of the ground motion in critical direction and $30 \%$ of the ground motion on the orthogonal direction. This combination rule considers neither soil characteristics nor correlation between ground motion components.

The simplicity of ELF procedure makes it open to investigation of its accuracy by numerous researchers [2-6]. Among these studies, Warn and Whittaker [5], and Ozdemir and Constantinou [6] focused on the response of isolated structures under bi-directional ground motion excitations. The main conclusion in Ref. [5] is that the coupled behavior of isolation systems increases isolator displacements by comparison to isolators modeled as uncoupled elements. Warn and Whittaker [5] also concluded that predictions of ELF procedure underestimate the maximum isolator displacements compared to results of bi-directional NRHA. On the other hand, Ozdemir and Constantinou [6] showed that ELF procedure gives reasonable estimates for maximum isolator displacements even for near-field conditions with a proper scaling of the records. Ozdemir and Constantinou [6] concluded that ELF procedure overestimates the maximum isolator displacements at soft soil sites.

${ }^{*}$ Corresponding author: Middle East Technical University K2 204 Ankara, 06531, Turkey. Tel.: +90 312 2105459; Fax: +90 3122107991 ; E-mail: han@metu.edu.tr. 
Table 1

Characteristics of near-field ground motions in Bin1

\begin{tabular}{|c|c|c|c|c|c|c|c|}
\hline Earthquake & Station & Magnitude $\left(\mathrm{M}_{w}\right)$ & $\mathrm{d}(\mathrm{km})$ & Component & PGA (g) & $\mathrm{PGV}(\mathrm{cm} / \mathrm{sec})$ & PGD $(\mathrm{cm})$ \\
\hline \multirow[t]{2}{*}{ Chi Chi (CC057) } & TCU057 & 7.6 & 11.8 & $\mathrm{~N}$ & 0.09 & 42.6 & 56.2 \\
\hline & & & & $\mathrm{W}$ & 0.12 & 35.2 & 56.7 \\
\hline \multirow[t]{2}{*}{ Cape Mendocino (CMP) } & Petrolia & 7.0 & 8.2 & 0 & 0.59 & 48.4 & 21.7 \\
\hline & & & & 90 & 0.66 & 89.7 & 29.6 \\
\hline \multirow[t]{2}{*}{ Duzce (DB) } & Bolu & 7.1 & 12 & 0 & 0.73 & 56.4 & 23.1 \\
\hline & & & & 90 & 0.82 & 62.1 & 13.6 \\
\hline \multirow[t]{2}{*}{ Gazli (GK) } & Karakyr & 6.8 & 5.5 & 0 & 0.61 & 65.4 & 25.3 \\
\hline & & & & 90 & 0.72 & 71.6 & 23.7 \\
\hline \multirow[t]{2}{*}{ Kocaeli (KG) } & Gebze & 7.5 & 10.9 & 0 & 0.24 & 50.3 & 42.7 \\
\hline & & & & 270 & 0.14 & 29.7 & 27.5 \\
\hline \multirow[t]{2}{*}{ Kocaeli (KI) } & Izmit & 7.5 & 7.2 & 180 & 0.15 & 22.6 & 9.8 \\
\hline & & & & 90 & 0.22 & 29.8 & 17.1 \\
\hline \multirow[t]{2}{*}{ Landers (LL) } & Lucerne & 7.3 & 2.2 & 275 & 0.72 & 97.6 & 70.3 \\
\hline & & & & 0 & 0.79 & 31.9 & 16.4 \\
\hline \multirow[t]{2}{*}{ Northridge (NN) } & Newhall & 6.7 & 5.9 & 90 & 0.58 & 75.5 & 17.6 \\
\hline & & & & 360 & 0.59 & 97.2 & 38.1 \\
\hline \multirow[t]{2}{*}{ Northridge (NR) } & Rinaldi & 6.7 & 6.5 & 228 & 0.84 & 166.1 & 28.8 \\
\hline & & & & 318 & 0.47 & 73.0 & 19.8 \\
\hline \multirow[t]{2}{*}{ Northridge (NS) } & Sylmar & 6.7 & 5.4 & 52 & 0.61 & 117.4 & 53.5 \\
\hline & & & & 142 & 0.90 & 102.8 & 47.0 \\
\hline \multirow[t]{2}{*}{ Tabas (TT) } & Tabas & 7.4 & 2.1 & LN & 0.84 & 97.8 & 36.9 \\
\hline & & & & TR & 0.85 & 121.4 & 94.6 \\
\hline
\end{tabular}

Success of ELF procedure to estimate response quantities under bidirectional excitations depends mainly on the contribution of orthogonal ground motion component. Thus, it has recently been studied by Tena-Colunga and Perez-Osornia [7] in detail by considering 154 pairs of records from 13 Mexican earthquakes with magnitudes greater than 6.4. In their research, Tena-Colunga and Perez-Osornia [7] studied an isolated 3-story reinforced concrete building with various isolation periods. However, authors considered ground motions recorded only in firm soil sites or rock and exclude motions recorded at soft soil sites. Moreover, the scaling procedure that Tena-Colunga and Perez-Osornia [7] followed is not appropriate for investigation of bi-directional response because, authors considered only the "so-called dominant ground component" to match the target spectrum at an arbitrarily selected period and used the calculated scale factor also for the other ground component. Nevertheless, scaling should be performed for a combination of both orthogonal horizontal components and should cover a range of periods rather than only one single period [8,9]. Furthermore, the scale factors employed in their studies were extremely high (up to 100) which may result in biased conclusions with due consideration of unrealistic ground motion records [10,11].

It is clear that there is a need to clarify the effect of soil condition on the contribution of orthogonal ground motion component. In the present study, contribution of orthogonal components in maximum isolator displacements are studied for records with near-field characteristics (i.e. directivity effect, pulse-like behavior) which are scaled to represent a target response spectrum to be consistent with the current requirements of ASCE [12]. Hence, a series of NRHA are performed both uni- and bi-directionally and conducted for two ground motion bins representing different soil conditions. The objective of this research is to identify the variation in contribution of orthogonal ground motion components due to change in soil conditions and to observe whether $100 \%+30 \%$ rule of ELF procedure in estimation of maximum isolator displacements is valid for the considered soil conditions or not.

\section{Selection and scaling of records}

The same sets of near-field ground motion records used in Ozdemir and Constantinou [6] were used in the present study. These records have been compiled from well known and extensively studied seismic events occurred in United States, Turkey, Iran, Taiwan, and former USSR. Records are classified in two groups according to their shear-wave velocities at the uppermost $30 \mathrm{~m}\left(\mathrm{~V}_{S, 30}\right)$ soil profile as per NEHRP. These ground motion sets are named as Bin1 $\left(360 \mathrm{~m} / \mathrm{sec}<\mathrm{V}_{S, 30}<760 \mathrm{~m} / \mathrm{sec}\right)$ and Bin2 $\left(180 \mathrm{~m} / \mathrm{sec}<\mathrm{V}_{S, 30}<360 \mathrm{~m} / \mathrm{sec}\right)$ and presented in Tables 1 and 2 , respectively. 
Table 2

Characteristics of near-field ground motions in Bin2

\begin{tabular}{|c|c|c|c|c|c|c|c|}
\hline Earthquake & Station & Magnitude $\left(\mathrm{M}_{w}\right)$ & $\mathrm{d}(\mathrm{km})$ & Component & PGA (g) & $\mathrm{PGV}(\mathrm{cm} / \mathrm{sec})$ & PGD $(\mathrm{cm})$ \\
\hline \multirow[t]{2}{*}{ Chi Chi (CC101) } & TCU101 & 7.6 & 2.1 & $\mathrm{~N}$ & 0.25 & 49.4 & 35.1 \\
\hline & & & & $\mathrm{W}$ & 0.20 & 67.9 & 75.4 \\
\hline \multirow[t]{2}{*}{ Erzincan (EE) } & Erzincan & 6.7 & 4.4 & NS & 0.52 & 83.9 & 27.4 \\
\hline & & & & EW & 0.50 & 64.3 & 22.8 \\
\hline \multirow[t]{2}{*}{ Imperial Valley (IVA4) } & Array 4 & 6.5 & 7.1 & 140 & 0.49 & 37.4 & 20.2 \\
\hline & & & & 230 & 0.36 & 76.6 & 59.0 \\
\hline \multirow[t]{2}{*}{ Imperial Valley (IVA5) } & Array 5 & 6.5 & 4.0 & 140 & 0.52 & 46.9 & 35.4 \\
\hline & & & & 230 & 0.38 & 90.5 & 63.0 \\
\hline \multirow[t]{2}{*}{ Imperial Valley (IVA6) } & Array 6 & 6.5 & 1.4 & 140 & 0.41 & 64.9 & 27.7 \\
\hline & & & & 230 & 0.44 & 109.8 & 65.9 \\
\hline \multirow[t]{2}{*}{ Imperial Valley (IVA10) } & Array 10 & 6.5 & 6.2 & 50 & 0.17 & 47.5 & 31.1 \\
\hline & & & & 320 & 0.22 & 41.0 & 19.4 \\
\hline \multirow[t]{2}{*}{ Kocaeli (KD) } & Duzce & 7.5 & 15.4 & 180 & 0.31 & 58.8 & 44.1 \\
\hline & & & & 270 & 0.36 & 46.4 & 17.6 \\
\hline \multirow[t]{2}{*}{ Kocaeli (KY) } & Yarimca & 7.5 & 4.8 & 60 & 0.27 & 65.7 & 57.0 \\
\hline & & & & 330 & 0.35 & 62.1 & 51.0 \\
\hline \multirow[t]{2}{*}{ Loma Prieta (LPCor) } & Corralitos & 6.9 & 3.9 & 0 & 0.64 & 55.2 & 10.9 \\
\hline & & & & 90 & 0.48 & 45.2 & 11.4 \\
\hline \multirow[t]{2}{*}{ Loma Prieta (LPSar) } & Saratoga & 6.9 & 8.5 & 0 & 0.51 & 41.2 & 16.2 \\
\hline & & & & 90 & 0.32 & 42.6 & 27.5 \\
\hline \multirow[t]{2}{*}{ Parkfield (PC) } & Cholame 2 & 6.0 & 14.3 & 90 & 0.60 & 63.3 & 14.1 \\
\hline & & & & 360 & 0.37 & 44.1 & 8.9 \\
\hline
\end{tabular}

\section{Combining horizontal components of ground motion records}

The most appropriate way to capture near-field effects (i.e. directivity effect) is to use distinct site spectra for both orthogonal horizontal components of ground motions [13]. Moreover, different scaling factors should be applied to orthogonal components of ground motions to match the related spectrum. However, at the design stage, it is most likely to have only one spectrum available. In such cases, available spectrum may be considered as the geometric-mean spectrum of two orthogonal directions [14]. Using geometric-mean of the response spectra for each horizontal component to combine into a single measure of shaking is one of the widely used method [8]. Nevertheless, there is a disadvantage of using geometric-mean of as-recorded motions: it depends on orientation of the sensors. Dependence of geometric-mean on sensor orientation is especially pronounced for periods greater than $1 \mathrm{sec}$. [8] which is in the range of interest when isolated structures are of concern. However, Boore et al. [8] developed two measures of geometric-mean that are independent of sensor orientation and concluded that differences between as-recorded geometric-mean and proposed two geometric-mean measures are less than 3\%. Having such a negligible difference, efforts are not directed to obtain these geometric-mean measures proposed by Boore et al. [8] and as-recorded motions are used. Furthermore, using as-recorded motions is not an unrealistic approach in terms of pulse-like behavior of near-field records. Krawinkler et al. [15] stated that even if horizontal components of the motions are rotated by $45^{\circ}$, one of the components is still as severe as the fault-normal component.

\section{Selection of target spectrum}

Majority of the modern seismic codes (i.e. ASCE [12]; IBC [16]) prescribe the use of RHA for isolated structures with a set of ground motions compatible with a target spectrum for such cases where the structure is at a distance less than $10 \mathrm{~km}$ to the fault rupture. However, they do not explicitly account for near-field characteristics (i.e. forward rupture directivity). On the other hand, for distances less than $10 \mathrm{~km}$ to fault, forward rupture directivity may be of concern. Bommer and Ruggeri [17] stated that near-field directivity effects are especially pronounced at long periods ( $>3 \mathrm{sec}$.). This statement is of crucial importance, because periods of the isolated structures are generally greater or equal to $2.0 \mathrm{sec}$. Hence, selected target spectrum should be capable of capturing the near-field effects.

This issue is discussed by Zekioglu et al. [18] in design of a specific large size isolated structure in Istanbul, Turkey. Authors compared a response spectrum, developed by probabilistic seismic hazard assessment (PSHA) of 
Table 3

Scale factors for both ground motion bins

\begin{tabular}{|c|c|c|c|c|c|c|c|}
\hline \multicolumn{4}{|c|}{ Bin1 } & \multicolumn{4}{|c|}{ Bin2 } \\
\hline Ground motion & Phase 1 & Phase 2 & Scale factor & Ground motion & Phase 1 & Phase 2 & Scale factor \\
\hline $\mathrm{CC} 057$ & 2.38 & 0.97 & 2.31 & $\mathrm{CC} 101$ & 2.89 & 0.84 & 2.43 \\
\hline CMP & 1.14 & & 1.10 & $\mathrm{EE}$ & 1.48 & & 1.24 \\
\hline DB & 0.95 & & 0.93 & IVA4 & 2.09 & & 1.75 \\
\hline GK & 1.35 & & 1.31 & IVA5 & 1.76 & & 1.48 \\
\hline KG & 2.67 & & 2.60 & IVA6 & 1.48 & & 1.24 \\
\hline KI & 2.77 & & 2.69 & IVA10 & 3.20 & & 2.70 \\
\hline LL & 1.76 & & 1.71 & KD & 2.07 & & 1.74 \\
\hline $\mathrm{NN}$ & 0.95 & & 0.93 & KY & 1.66 & & 1.39 \\
\hline NR & 0.70 & & 0.68 & LPCor & 2.62 & & 2.20 \\
\hline NS & 0.61 & & 0.60 & LPSar & 2.87 & & 2.41 \\
\hline TT & 0.93 & & 0.90 & PC & 2.05 & & 1.73 \\
\hline
\end{tabular}
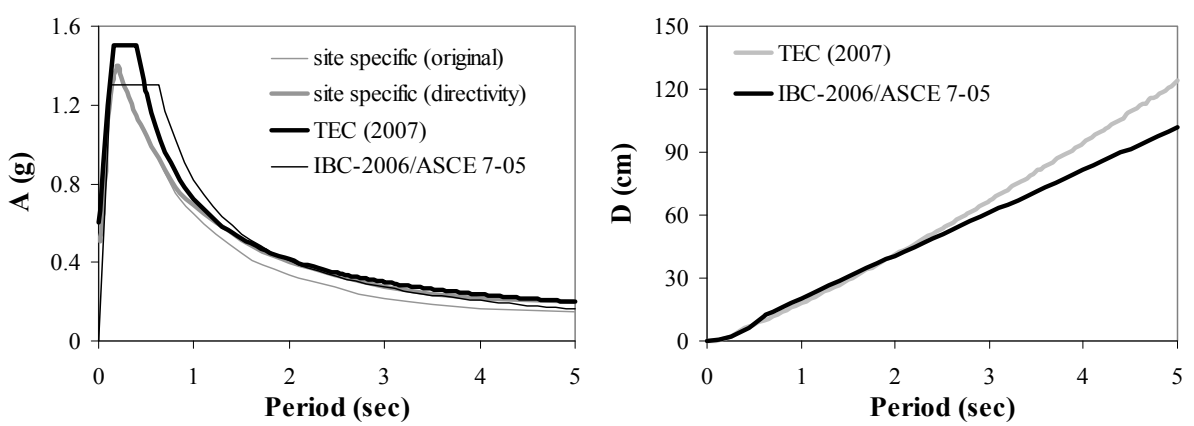

Fig. 1. a) Comparison of site-specific response spectrum with those of IBC-2006, ASCE-7-2005 and TEC-2007 (adopted from Zekioglu et al., 2009) b) Comparison of spectral displacements of TEC-2007 and IBC-2006/ASCE-7-2005.

the construction site (with and without directivity effect) conducted by Erdik et al. [19] for maximum considered earthquake (MCE) level, with those prescribed by the seismic codes (Fig. 1.a). The amplification in ground acceleration at a period of $2.5 \mathrm{sec}$. is $20 \%$ when directivity effect is included [19]. Figure 1.a shows that $5 \%$-damped elastic spectrum prescribed by ASCE [12] and IBC [16] under-estimates the developed response spectrum at periods higher than $2.0 \mathrm{sec}$. whereas the one suggested by Turkish Earthquake Code (TEC) [20] is slightly higher than the developed one. Figure 1.b clearly shows the difference between spectral displacements of TEC [20] and the others which indicates that the use of spectrum prescribed by TEC [20] is more conservative for longer period ranges. Figure 1.a shows that response spectrum prescribed by TEC [20] can be used in RHA of seismic isolated structures even under near-field conditions. Use of response spectrum to capture the directivity effects observed in near-field records is also encouraged by Malhotra [21] and Chopra and Chintanapakdee [22]. Thus, 5\%-damped response spectra prescribed by TEC [20], for the clustered two ground motion bins, are selected.

\section{Followed scaling procedure}

In this study, the followed scaling procedure is composed of two complementary phases as described in Ozdemir and Constantinou [6]. In the first phase, selected ground motion records become compatible with the target spectrum whereas the second part assures the requirement of the codes for RHA. The final scaling factor applied to each ground motion is obtained by multiplication of two factors obtained in two scaling phases. These final scaling factors are given in Table 3 for both ground motion bins. Computed scaling factors are applied to both horizontal components of motions to preserve the difference in between. Figure 2 presents the $0.9 \times 1.3 \times 5 \%$-damped target spectra and average SRSS of eleven ground motion records scaled as described above for both ground motion bins. The employed scaling factors are all smaller than the normally accepted upper limit of four for a scaling factor $[10$, $14]$ in order not to introduce any bias on results. 
Table 4

Parameters for isolation systems considered in this study

\begin{tabular}{lr}
\hline Post-yield period, $T$ (sec) & $3.0,3.5,4.0$ (for Bin1) 3.5, 4.0, 4.5 (for Bin2) \\
\hline Strength to Weight Ratio, $Q / W$ & $0.04,0.06,0.08,0.10$ (for Bin1) 0.08, 0.10, 0.12, 0.14 (for Bin2) \\
\hline
\end{tabular}
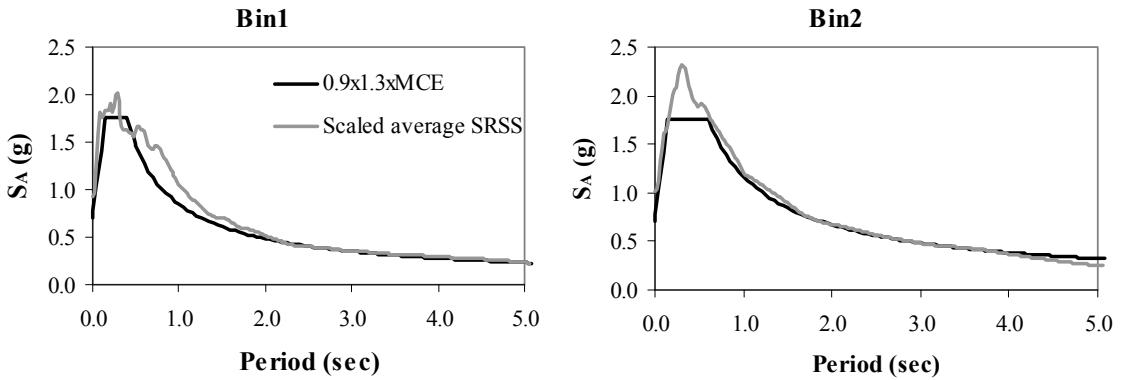

Fig. 2. Final scaling of ground motion records.

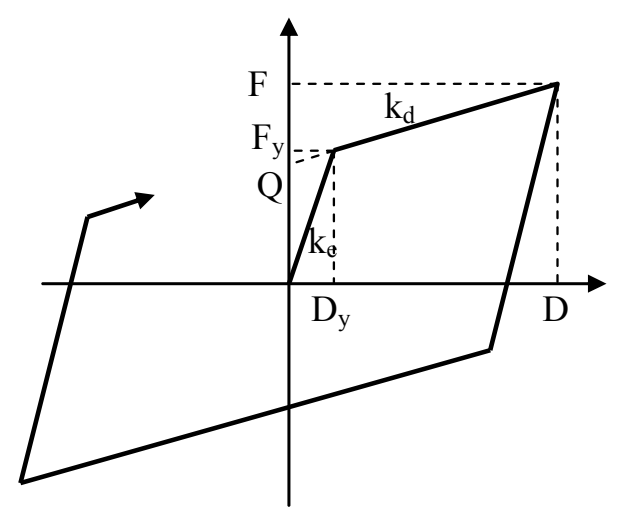

Fig. 3. Bi-linear force-deformation relation of an isolator.

\section{Modeling of isolators}

Isolation systems considered in this study are composed of LRB and represented by a generic bi-linear hysteretic behavior without considering cycle-to-cycle deterioration. Idealized force-deformation relation is given in Fig. 3 where $Q$ is the characteristic strength, $k_{d}$ is the post-yield stiffness, and $k_{e}$ is the initial elastic stiffness. $F_{y}$ and $D_{y}$ are the yield force and yield displacement, respectively. Table 4 presents the considered values of parameters used in NRHA as described in detail in [6].

Simulations of LRB behavior are performed by means of structural analysis program SAP2000 [23] where nonlinear link elements are utilized to model bi-linear force-deformation relations of isolators. Employed link elements developed by Park et al. [24], have coupled plasticity properties for both of the deformations in orthogonal horizontal directions.

\section{Modeling of superstructure}

Analyzed RC structure is identical to the structure studied by Ozdemir and Constantinou [6]. The plan dimensions are $16 \mathrm{~m} \times 10.5 \mathrm{~m}$ and height of each floor is same and equals to $2.9 \mathrm{~m}$. Figure 4 shows the idealized 3-D model of 3 -story isolated RC building. In the analyses, superstructure is modeled as elastic. This is a reasonable assumption because "the isolation attempts to reduce the earthquake response in such a way that the structure remains within the elastic range" [25]. 


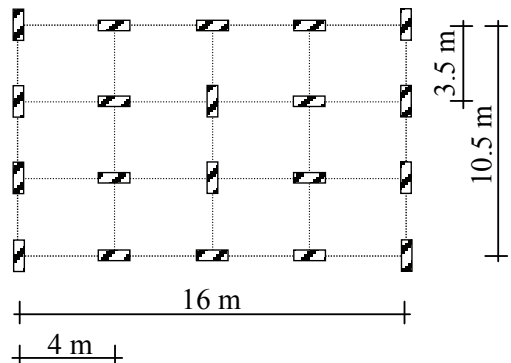

(a)

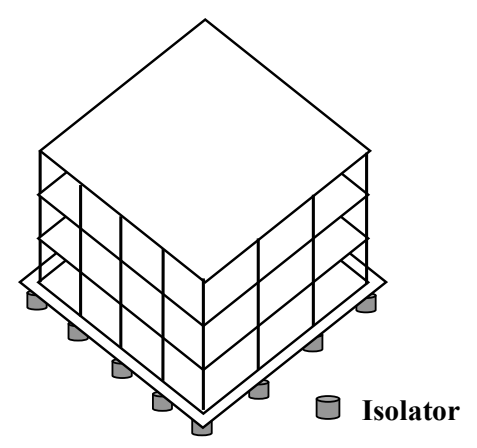

(c)

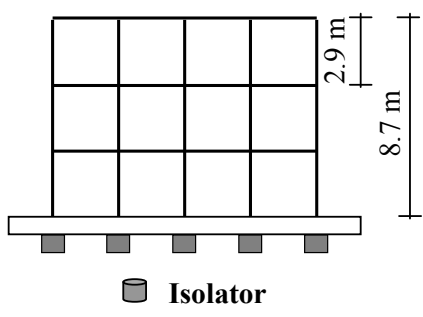

(b)

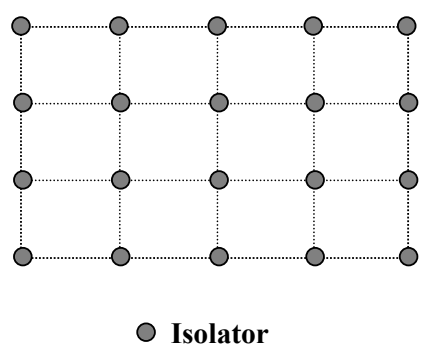

(d)

Fig. 4. 3-D model of 3-story isolated RC building: (a) plan, (b) elevation, (c) 3D layout, and (d) isolation system.

\section{Equivalent lateral force procedure}

Simplified method of analysis namely, ELF procedure, prescribed by code specifications for design of seismically isolated structures is an iterative method and considers only one-directional analysis based on a target response spectrum. Iteration starts with an assumption for isolator displacement $d$ for the selected isolation period and $Q / W$ ratio. These values together with the assumed $d$ are then used to calculate the properties of equivalent elastic system $\left(k_{e f f}, T_{e f f}, \beta_{e f f}\right)$ as described in Eq. (1). Effective damping ratio $\beta_{\text {eff }}$ is needed to determine damping reduction factor $B$ which is used to modify $5 \%$-damped response spectrum for damping ratios higher than $5 \%$. The maximum isolator displacement $d_{u n i}$ is calculated by using the representative linear properties as in Eq. (2) where, $S_{a}$ is the spectral acceleration for the corresponding $T_{e f f}$. Once the assumed $d$ and calculated $d_{u n i}$ are close enough, iteration ends. Otherwise, iteration continues with a new assumption for $d$. The total maximum isolator displacement $d_{b i}$ is calculated by Eq. (3) in accordance with $100 \%+30 \%$ rule as per ASCE [12].

$$
\begin{aligned}
& k_{e f f}=k_{d}+\frac{Q}{d}, T_{e f f}=2 \pi \sqrt{\frac{W}{k_{e f f} g}}, \beta_{e f f}=\frac{2 Q\left(d-D_{y}\right)}{\pi k_{e f f} d^{2}} \\
& d_{u n i}=\frac{g S_{a} T_{e f f}^{2}}{4 \pi^{2} B} \\
& d_{b i}=d_{u n i} \times\left(\sqrt{1^{2}+0.3^{2}}\right) \approx 1.045 d_{u n i}
\end{aligned}
$$

\section{Nonlinear response history analyses results}

A set of NRHA are conducted under uni- and bi-directional earthquake excitations. For uni-directional analyses, both of the orthogonal horizontal components of motions were applied individually whereas they were applied simultaneously for bi-directional analyses. Maximum isolator displacements obtained from both uni- and bi- 


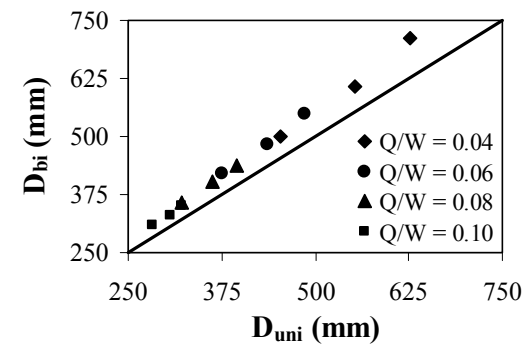

(a)

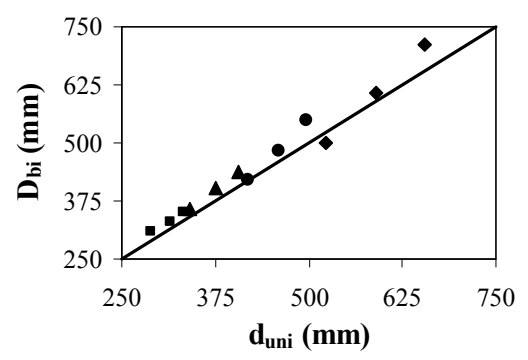

(b)

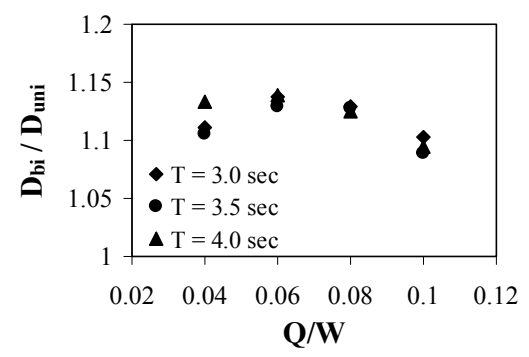

(c)

Fig. 5. Comparison of $D_{b i}$ and $D_{u n i}$ obtained from NRHA with $d_{b i}$ and $d_{u n i}$ calculated as per ASCE (2005) regarding ground motions in Bin1.

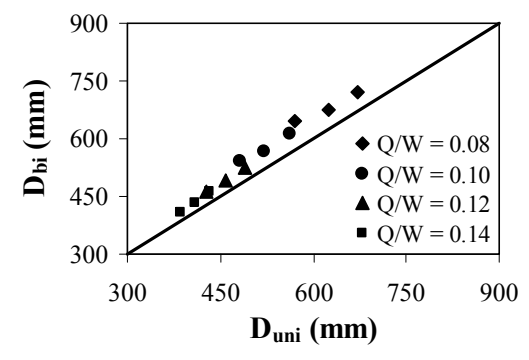

(a)

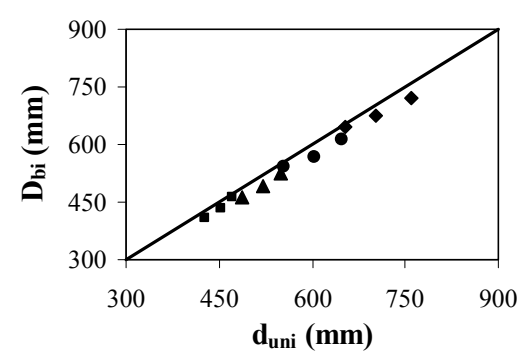

(b)

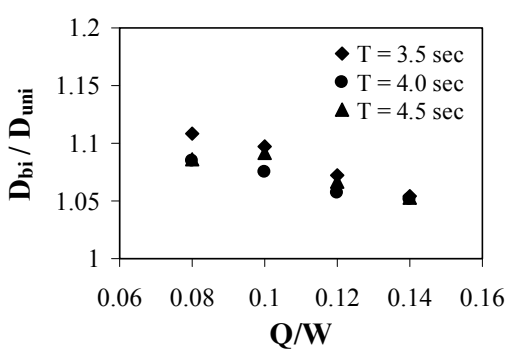

(c)

Fig. 6. Comparison of $D_{b i}$ and $D_{u n i}$ obtained from NRHA with $d_{b i}$ and $d_{u n i}$ calculated as per ASCE (2005) regarding ground motions in $\operatorname{Bin} 2$.

directional excitations are compared with each other and with calculations of ELF procedure $\left(d_{u n i}\right.$ and $\left.d_{b i}\right)$. All of the plots in this section show only the average of the results for all records.

In Figs 5 and 6, $D_{b i}$ stands for the maximum isolator displacements obtained from bi-directional analyses and determined from the SRSS of displacement response calculated at each time step during the RHA. On the other hand, $D_{\text {uni }}$ represents the maximum isolator displacements obtained from uni-directional analyses and equals to 
maximum isolator displacements observed at any of the horizontal direction under individually applied uni-directional excitations. To identify the contribution of orthogonal component on the isolator displacements, $D_{b i}$ is further normalized by $D_{u n i}$ for each individual ground motion and then presented in an average sense.

In Figs 5.a and 6.a, $\left(D_{b i}\right)_{a v g}$ is plotted against $\left(D_{\text {uni }}\right)_{a v g}$ as a function of $Q / W$ ratio to investigate the variation of orthogonal components on maximum isolator displacements. Figures 5.a and 6.a indicate that the difference between $\left(D_{b i}\right)_{a v g}$ and $\left(D_{u n i}\right)_{a v g}$ decreases as $Q / W$ increases for both ground motion bins. $\left(D_{b i}\right)_{a v g} /\left(D_{u n i}\right)_{a v g}$ ratios of both ground motion bins are almost identical and are roughly in between 7\%-14\%. Here, ()avg is used to describe the average of the term enclosed in parenthesis. Although $\left(D_{b i}\right)_{a v g} /\left(D_{u n i}\right)_{a v g}$ ratios of both ground motion bins are very close to each other and vary in a similar range, it is interesting to observe such a variation in the success of ELF procedure based on the soil condition [6]. According to [6], ELF procedure overestimates the maximum isolator displacements for Bin 2 while its predictions are very close to ones obtained from NRHA for Bin1. Estimations of ELF procedure for various $Q / W$ and $T$ are very close to maximum isolator displacements obtained from NRHA for Bin1 (mean of $D_{b i} / d_{b i}$ is 1.00 with a standard deviation of 0.038 ). When the same comparison is done for Bin2 ELF procedure overestimates the results obtained from NRHA (mean of $D_{b i} / d_{b i}$ is 0.92 with a standard deviation of 0.016) [6]. It is clear that the accuracy of ELF procedure is not invariant to clustered ground motion bins. To understand whether this difference is due to $100 \%+30 \%$ or not, $\left(D_{b i}\right)_{a v g}$ are plotted against $d_{u n i}$ in Figs 5.b and 6.b for Bin1 and Bin2, respectively. These figures indicate that $d_{\text {uni }}$ underestimates the maximum isolator displacements for Bin1 whereas it gives accurate enough estimations for Bin2.

It is interesting to observe such a difference between $D_{b i}-d_{b i}$ and $D_{b i}-d_{u n i}$ relations of considered two ground motion bins even though the $\left(D_{b i}\right)_{a v g} /\left(D_{u n i}\right)_{a v g}$ ratios of each bin are close to each other with minor differences. To shed light on this phenomenon, $\left(D_{b i} / D_{u n i}\right)_{a v g}$ of Bin1 and Bin2 are plotted against $Q / W$ in Figs 5.c and 6.c, respectively. For Bin1, $\left(D_{b i} / D_{u n i}\right)_{a v g}$ are in between 10\%-15\%, whereas they are in between 5\%-10\% for Bin2. This inference indicates that the contribution of orthogonal components of motions in Bin1 is higher than that of Bin2. As a result, $100 \%+30 \%$ rule for ELF procedure seems appropriate to estimate maximum isolator displacements for Bin1 while any increase in one-directional estimation of ELF procedure is not needed for Bin2 (see Fig. 6.b).

\section{Conclusions}

In this study, NRHA of an isolated 3-story RC building are carried out under uni- and bi-directional earthquake excitations of near-field records. Two sets of near-field ground motion records are used, and each set have eleven records clustered according to shear wave velocities at the uppermost $30 \mathrm{~m}$ soil profile. Selected near-field ground motions are used to identify the variation in contribution of orthogonal ground motion components due to change in soil conditions and to observe whether $100 \%+30 \%$ rule of ELF procedure in estimation of maximum isolator displacements is valid for the considered soil conditions or not. The following conclusions can be revealed from the results of the present study:

- Contribution of orthogonal components of records on maximum isolator displacements is affected by the soil condition of the ground motion. It is higher in stiffer (Bin1) soil conditions compared to softer (Bin2) ones. $\left(D_{b i} / D_{u n i}\right)_{a v g}$ varies in between 1.10 and 1.15 for Bin1 whereas it is in the range of 1.05-1.10 for Bin2.

$-100 \%+30 \%$ rule may lead to overestimation of maximum isolator displacements based on the soil classification. $100 \%+30 \%$ rule for ELF procedure seems appropriate to estimate maximum isolator displacements for Bin 1 while any increase in one-directional estimation of ELF procedure is not needed for Bin2

\section{Acknowledgments}

The authors acknowledge both the Scientific and Technological Research Council of Turkey (TUBITAK), and Turkish State Planning Organization for sponsoring the graduate studies of first author. 


\section{References}

[1] M. Dicleli, Seismic design of a lifeline bridge using hybrid seismic isolation, Journal of Bridge Engineering (ASCE) 7(1) (2002), 94-103.

[2] W.D. Iwan and N.C. Gates, Estimating earthquake response of simple hysteretic structures, Journal of the Engineering Mechanics Division 105(EM3) (1979), 391-405.

[3] A.K. Chopra and R.K. Goel, Evaluation of NSP to estimate seismic deformation: SDF systems, Journal of Structural Engineering (ASCE) 126(3) (1999), 482-490.

[4] O.M. Ramirez, M.C. Constantinou, A.S. Whittaker, C.A. Kircher and C.Z. Chrysostomou, Evaluation of simplified methods of analysis of yielding structures with damping systems, Earthquake Spectra 18(2) (2002), 531-547.

[5] G.P. Warn and A.S. Whittaker, Performance estimates in seismically isolated bridge structures, Engineering Structures 26(9) (2004), 1261-1278.

[6] G. Ozdemir and M.C. Constantinou, Evaluation of equivalent lateral force procedure in estimating seismic isolator displacements, Soil Dynamics and Earthquake Engineering 30(10) (2010), 1036-1042.

[7] A. Tena-Colunga and M.A. Perez-Osornia, Design displacements for base isolators considering bidirectional seismic effects, Earthquake Spectra 22(2) (2006), 803-825.

[8] D.M. Boore, J. Watson-Lamprey and N.A. Abrahamson, Orientation-independent measures of ground motion, Bulletin of the Seismological Society of America 96(4A) (2006), 1502-1511.

[9] C.B. Haselton and J.W. Baker, Ground motion intensity measures for collapse capacity prediction: choice of optimal spectral period and effect of spectral shape. Proceedings of the Eighth US National Conference on Earthquake Engineering, 2006, San Francisco, California.

[10] J.J. Bommer and A.B. Acevedo, The use of real earthquake accelerograms as input to dynamic analysis, Journal of Earthquake Engineering 8(Supp 1) (2004), 43-91.

[11] J. Hancock, J.J. Bommer and P.J. Stafford, Numbers of scaled and matched accelerograms required for inelastic dynamic analyses, Earthquake Engineering and Structural Dynamics 37(14) (2008), 1585-1607.

[12] American Society of Civil Engineers (ASCE). Minimum design loads for buildings and other structures, Standard ASCE/SEI 7-05, 2005, Reston, VA.

[13] J.P. Stewart, S.-J. Chiou, J.D. Bray, R.W. Graves and P.G. Somerville, Abrahamson NA. Ground motion evaluation procedures for performance-based design, PEER Report 2001/09, Pacific Earthquake Engineering Research Center, 2001, University of California, Berkeley.

[14] P.K. Malhotra, Strong-motion records for site-specific analysis. Earthquake Spectra 19(2) (2003), 557-578.

[15] H. Krawinkler, B. Alavi and F. Zareian, Impact of near-fault pulses on engineering design, directions in strong motion instrumentation. published by Springer and edited by Polat Gulkan and John G. Anderson, 2005.

[16] International Building Code (IBC), International Code Council 2006, Country Club Hills, Illinois.

[17] J.J. Bommer and C. Ruggeri, The specification of acceleration time-histories in seismic design codes, European Earthquake Engineering 16(1) (2002), 3-17.

[18] A. Zekioglu, H. Darama and B. Erkus, Performance-based seismic design of a large seismically isolated structure: Istanbul Sabiha Gökçen International Airport Terminal Building. SEAOC Convention Proceedings 2009, available at http://www.ejge.com/Sabiha/ 2009_SEAOC_ArupLA.pdf.

[19] M. Erdik, K. Sesetyan, M.B. Demircioglu and E. Durukal, Assessment of site-specific earthquake hazard for the new International Terminal of Sabiha Gökçen Airport (Internal Report). Bogazici University, 2008, Istanbul, Turkey.

[20] Turkish Earthquake Code (TEC). Specifications for the buildings to be constructed in disaster areas. Ministry of Public Works and Settlement, Ankara, Turkey, 2007.

[21] P.K. Malhotra, Response of buildings to near-field pulse-like ground motions, Earthquake Engineering and Structural Dynamics 28(11) (1999), 1309-1326.

[22] A.K. Chopra and C. Chintanapakdee, Comparing response of SDF systems to near-fault and far-fault earthquake motions in the context of spectral regions, Earthquake Engineering and Structural Dynamics 30(12) (2001), 1769-1789.

[23] Computers and Structures, Inc. SAP 2000 Nonlinear, Version 12.0.0, Structural Analysis Program 2008, Berkeley, CA.

[24] Y.J. Park, Y.K. Wen and A.H. Ang, Random vibration of hysteretic systems under bi-directional ground motions, Earthquake Engineering and Structural Dynamics 14(3) (1986), 543-557.

[25] V.A. Matsagar and R.S. Jangid, Influence of isolator characteristics on the response of base-isolated structures, Engineering Structures 26(12) (2004), 1735-1749. 

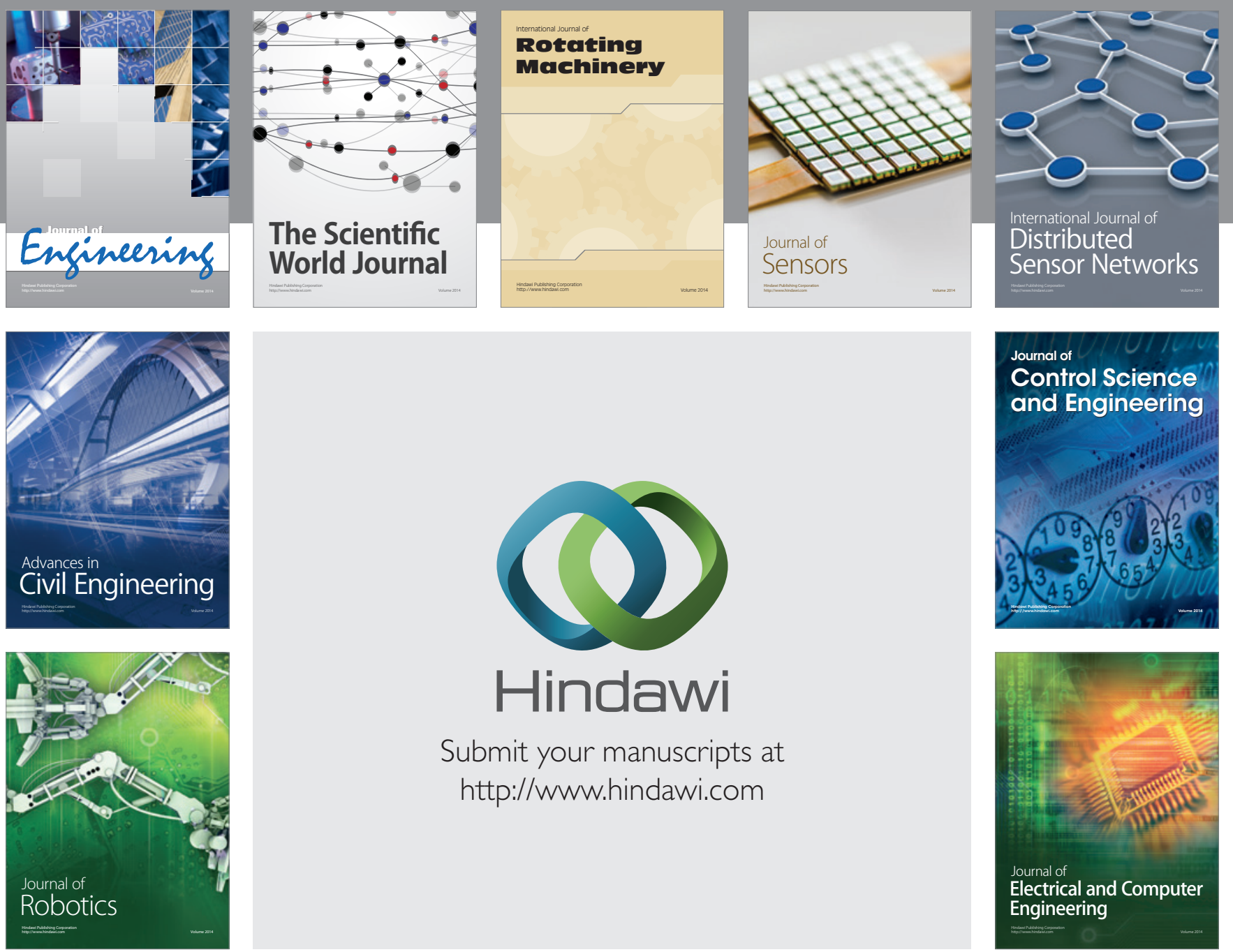

Submit your manuscripts at

http://www.hindawi.com
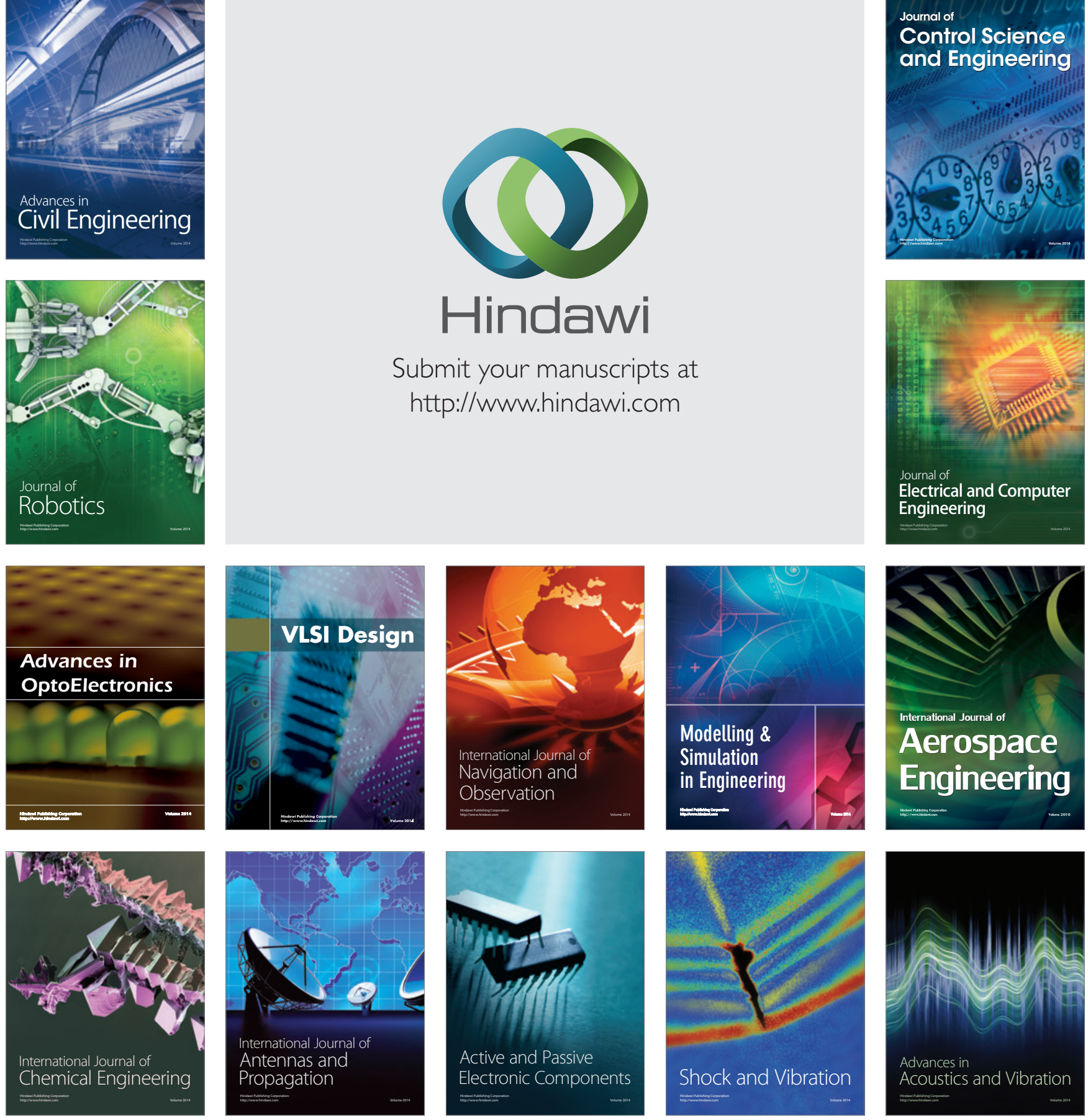